\title{
The Effect of Organizational Culture on Knowledge Management and Managerial Performance of Government Department in Dubai
}

\author{
Mohamed Saif Rashid \\ Nek Kamal Bin Yeop \\ Faculty of Management \& Economics, University Pendidikan Sultan Idris, Tanjung Malim. Malaysia
}

\begin{abstract}
This study aim to emphasize the importance of knowledge management and the factors that influence the knowledge management within Dubai public sector organization. The study is to highlight the effect of organizational culture on the relationship between knowledge management and managerial performance of government departments in Dubai. Development of organizational culture is pegged on managerial performance. The role of the manager in any department is to evaluate the system and eliminate the impediments to success.As long as the mindset is built on competitive spirit, employees will be nurtured to appreciate superior performance amid their challenges. The manager should also act as a problem solver by understanding the existing challenges and using the available knowledge to create feasible solutions Data were collected by distributing questionnaires to 215 systematic randomly sampled respondents from seven public departments. Data collected were analyzed by using descriptive and inferential statistics. The research showed that the effect of organizational culture on knowledge management and managerial performance of government department in Dubai.
\end{abstract}

Keywords: Knowledge Management, Organization, Culture, Performance.

\section{Introduction}

Organizational culture has been linked to high levels of performance in any entity whether public or private. On the other hand, knowledge management has been perceived as a strong element in building competitive advantage. In fact, it is considered a strategic asset for ensuring desired levels of performance are achieved. The era of globalization has led to a knowledge-based economy where organizations need to pursue strategic actions. Government organizations have often been linked with redundancies as compared to the private entities. However, governments across the globe are seeking ways of revamping their performance. Governments like the UAE have realized that knowledge is one of the most valuable assets in bolstering productivity of employees (Radwan \& Milhem, 2015). The element of knowledge management should be embedded in the organizational culture for the desired deliverables to be guaranteed. The merit of knowledge management is the guarantee in building a culture of learning.

The UAE is a good example of countries that have recognized the value of knowledge management practices. The government has invested significant resources in developing the ICT infrastructure to bolster knowledge management. The culture of excellence in the UAE federal government has culminated into innovative practices to guarantee the desired change (Ngah, Tai, \& Bontis, 2016). Knowledge management has become an integral element to the reform paradigms in the region leading to good governance, smart leadership, and positive reputation.

\section{Problem Statement}

Knowledge management in Dubai has been one of the core pursuits towards achieving economic growth. The government has made deliberate effort in developing knowledge management practices that are aligned to the UAE Vision 2021. The theme of 'United in Knowledge' has helped the country to find suitable indicators to evaluate the milestones in developing a knowledge economy (Jahmani, Fadiya, Abubakar, \& Elrehail, 2018). For instance, the global innovation index (GII) and the recruitment index for knowledge field employees have proved fundamental. The development of excellence awards for federal entities have also triggered continued development and learning. In fact, the Mohammed bin Rashid Government 
Excellence Award has been a platform for evaluating performance results for public entities as they adjust their systems towards knowledge management and innovative practices. The Mohammed Award is also complemented by the Emirates Award for Human Resources in the Federal Government.

The element of knowledge management has been incorporated in the organizational culture of federal entities in Dubai based on the dynamism in the business climate. The advancement of technology has triggered new ways of dealing with public expectations and stakeholder interests. The fierce competition with other countries and the need to remain relevant in the globalized world has added meaning to the popularity of knowledge management. The government has been keen on optimal operations that seek to reduce costs and increase productivity among employees. Knowledge generation has been guaranteed through investments in research and other experimental initiatives conducted in academic institutions, public entities, and other private organizations (Singh, 2017). The government has been a critical player in knowledge generation through its reforms and investments in research. Knowledge storage relates to the manner in which data is availed in either soft or hard copy to facilitate easy retrieval by the stakeholders. The government has been playing an important role of technical infrastructure to support knowledge repositories. In this case, different stakeholders can search information, retrieve the knowledge without any challenges. Therefore, the flawless infrastructure is crucial in saving time and improving performance in the organizations as they seek to access knowledge on different issues.

While knowledge management is a vital pursuit for governments seeking positive change in the dynamic world, it has to be aligned to the organizational culture. Organizational culture depicts the values, principles, and norms that should be embraced to provide identity to an entity. A strong organizational culture is built on positive beliefs, values, and practices. For most countries, the culture of public entities is marred with negativities based on redundancies and other elements of poor performance (Birasnav, Goel, \& Rastogi, 2012). The modern business environment across the globe dictates flexibility to change and efficiency in varied practices. In fact, the knowledge-based economy is driven by dynamism and departure from bureaucratic structures. The goal is to encourage a culture of productivity, flexibility, efficiency, and innovation in the public sector. The government leaders are encouraged to embrace a flexible mindset to build strong cultures in the tainted public entities. They are supposed to rethink their strategies relative to the private sector entities that are known to exhibit efficiency in their operations.

Development of organizational culture is pegged on managerial performance. On the other hand, managerial performance is influenced by a myriad of issues, such as leaders' personal attributes, experiences, and education. The role of the manager in any department is to evaluate the system and eliminate the impediments to success. The exposure of a manager to knowledge enables him or her to influence the existing conditions in the business environment to such an extent that competitiveness is enhanced (Haak-Saheem \& Darwish, 2014). A manager with rich information about the globalized world has the capability of developing a unique culture in the department. As long as the mindset is built on competitive spirit, employees will be nurtured to appreciate superior performance amid their challenges. The manager should also act as a problem solver by understanding the existing challenges and using the available knowledge to create feasible solutions. As one of the thriving metropolitan regions in the world, UAE is characterized by diversity. In this case, culture is necessary to accommodate the pool of expatriates who are core elements in the process of knowledge transfer and share.

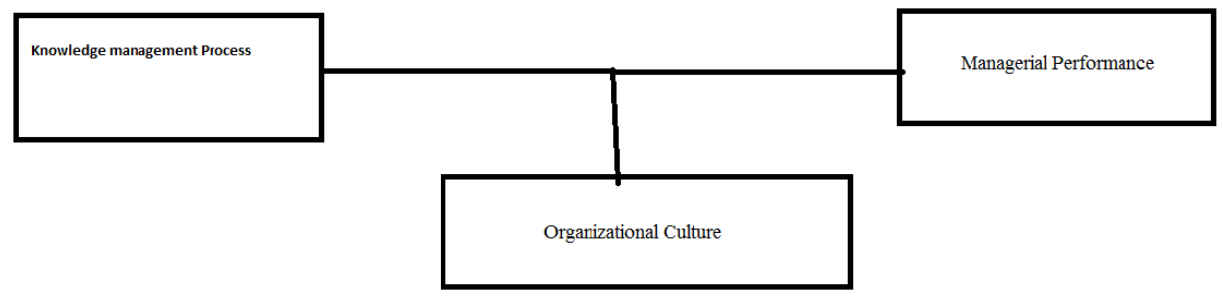

Significance of Study (Contribution) 
The significance of the study is to outline the manner in which culture affects knowledge management and influence managerial performance. The scope of the research revolves around the public entities. In this case, the logic of cultural knowledge management emerges while assuming certain values must be cultivated within the public entities. The study will reveal the way knowledge management processing affects culture by exposing leaders to information about positive practices. For instance, it is possible for leaders to learn about positive aspiration, reciprocity of trust, and the motivations of knowledge exchange. These values are necessary in creating a culture of learning (Rahman, Moonesar, Hossain, \& Islam, 2018). On the other hand, managerial performance can be affected by insisting on a culture of negative competition and poor transfer or share of knowledge. The study aims at showing how culture dictates the kind of processes and practices that should be part of the knowledge-based system. Most of the organizations are run through the suppositions of the leader. Therefore, knowledge management is meant to provide a support system of facts to back the decisions of the manager. The study also insists on the element of knowledge possession among the managers in organizations. Managers' perceptions of their personal knowledge could create or impede trust among the employees. Consequently, the norms embedded in the organizational culture could be responsible for the mindset of employees and managers towards change and fortification of the knowledge-based system. Furthermore, the study reveals the effect of the varied forms of organizational culture on the dimensions of knowledge management.

\section{Literature Review}

\subsection{The Effect of Knowledge Management on Managerial Performance}

Organizations need to tap into their knowledge assets as part of a management process aimed at refining strategic needs. The forms of knowledge define information that build an organization's knowledge assets and the projection through individual perceptions and personal experiences. The emergence of knowledge management aligns with the ability to drive profitability and efficiency within organizations with critical interest on managerial performance. Knowledge management provides the building blocks for managerial performance with the opportunity to reinforce task execution through the explicit, tacit, and embedded knowledge types (Alsadhan, Zairi, \& Keoy, 2008). Areas of interest in the development of managerial criteria include the existence of technical capabilities, managerial capabilities, human capabilities, and conceptual capabilities that define the vision and direction for the organization. Within the public and private sectors, performance management systems are put in place to guide the execution of the vision from which the managerial criteria can be analyzed. Managerial capabilities put to task include the ability to plan, organize, coordinate, monitor, control, and supervise based on the harnessed knowledge. Furthermore, managerial performance is refined by focusing on technical capabilities expressed through methods, processes, procedures, and techniques an organization deploys to instill sustainable performance. The opportunity to deal with human capital continues to develop performance appraisal with interest in refining performance areas, instill self-appraisal, and apply performance rating using reliable analyses criteria. Consideration for information and organization capital are also expected as the organization grows its databases, information systems, corporate culture, and leadership that can sustain vision execution. Through managerial performance, knowledge management become alive with the opportunity to exploit greater opportunities in terms of transfer of information and building of intellectual assets.

Performance planning is part of managerial performance where focus is drawn towards the systematic drafting of activities leaders will execute within a period where a project needs to be implemented. Information contained within knowledge systems provides a guideline on what to expect starting with task analysis, key performance areas, key result areas, task and target identification, action plans, and goal setting. Knowledge management provides a backing in this regard especially when leaders understanding the efficiencies contained within the organization's embedded knowledge (Brahma \& Mishra, 2015). Performance planning works better with an understanding of routines defined through the relationship between information technology and the functional areas of a business that build processes and procedure. Furthermore, performance planning needs to align with organizational regulations, procedures, ethical codes, and corporate culture that is at the heart of the institutional system. Aspects of performance planning such as key performance areas are at the core of managerial performance based on the timelines used to define project fulfillment and ability to focus on individualized employee assessments. Use of knowledge systems to improve employee performance is guided by the level of assessments based on key performance areas with interest in replicability of successful strategies. Under the Federal Authority for Government Human Resources in the UAE, systems such as Bayanati are known to be successful based on their ability to replicate successful administrative procedures (Rahman, Moonesar, Hossain, \& Islam, 2018). The management of human resources is also incorporated into the system ranging from recruitment to wage and salary 
procedures, workplace mobility, and retirement plans. The holistic view of human resources management quantifies and qualifies the usefulness of employees which is critical indicator in managerial performance. Governments are able to manage knowledge production based on the level of control on human resources where ideas, skills, and experiences are exchanged to establish organizational continuity.

\subsection{The Effect of Organizational Culture on Managerial Performance}

Organizational culture can be worked out of the knowledge management concept. The creation of beliefs, assumptions, and leadership ideals that guide an organization's vision are part of information system within an organization that pushes for an idealized image. Cultural dispensations are guided by shared attitudes, customs, and organizational regulations stipulated based on the vision, values, and norms an organization aspires to as part of the strategy. Organizational culture links to managerial performance once the strategies are operationalized indicating the need to bring out employee knowledge in strategy execution (Boumarafi, 2009). The development of organizational cultures positions employees for success especially when the training process aligns with the vision and purpose. The ability to influence behavior to suit a particular vision is critical for performance growth and can be tracked using the performance appraisal function. In addition, the feedback loop defines the type of interaction the manager carries out when dealing with employees which defines the role of communication in advancing successful value systems. In the different knowledge integration stage, managers are able to provide instructions and guides or procedures that have worked. The combination between explicit and tacit knowledge may define a different path in organizational culture with a distinct outcome on managerial performance. Creation of new tacit knowledge guides the type of engagement a leader is able to create with employees and the importance of creating learning systems to instill continuity (Haak-Saheem, \& Darwish, 2014). Leaders have the opportunity to build sustainable organizational cultures based on performance indicators such as their understanding of core competencies of their employees. Environmental factors need to incorporate into the development of organizational culture with a push for a learning organization able to attain innovation and market disruption. Deployment of performance counselling is necessary based on the need to communicate effectively, influence, and create workplace models to help build trust, professional growth, and identify needs. Employees gain workplace competence based on their ability to compete, gain knowledge, and achieve psychological balance which emanate from the composition of the organization's culture. For instance, managers have the ability to influence based on their style of leadership that defines their application of emotional intelligence, positive reinforcement, and open communication that builds the mutuality of relationships. The response from employees aligns with creativity, innovativeness, effective knowledge sharing, teamwork, and participation in decision-making.

\section{Instruments (Questionnaire)}

After reviewing the literature on the topic, the questionnaire developed for this study is a closed-ended type. The questionnaire was finalized in two parts as follows: Section I: Included the demographic data of the study sample using five main categories; (age, gender, education level, position and years of experiences). Section II: included one sub-section where it consists of the four Knowledge Management processes. The questionnaire scale that measure each variable was designed after examining a number of previous studies in order to come up with a suitable indicators for each variable. These studies helped formulating the final questionnaire (Ahmed, Fiaz \& Shoaib, 2015; Downes, 2014; Edwards, Handzic, Carlsson \& Nissen, 2003; Lee \& Choi, 2003).

\subsection{KM Indicators Contribution to the prediction of OP.}

The empirical results presented in Table 1 indicate a sufficiently good model fit. According to the R score, it can state that $(0.745)$ or $74.5 \%$ of the Dependent variable (OP) is explained by the four independent variables namely Knowledge generation (KG), Knowledge storage and retrieval (KSR), Knowledge transfer and Share (KTS) and Knowledge Application (KA).

Although the $\mathrm{R}$ score indicates that there is a significant influence among the four indicators, the R-square score which is close to $55 \%$ shows that this statement might be questionable. The Significant level also indicates that there is a Statistical significance for the model. It's shown that it has a score of zero which is below the acceptable level of $(0.05)$ or $5 \%$.

Table 1: Summary of the KM indicators contribution to the prediction of OP. 


\section{$\mathrm{R}$}

R Square

Adjusted R Square

Sig.

0.745

0.555

0.552

0.000

Dependent Variable: OP

Independent variables: KG,KSR,KTS, and KA

\section{KM Indicators Contribution to the prediction of OP.}

According to the analysis in table 1 and 2 the $\mathrm{R}$ square for $\mathrm{KM}$ and $\mathrm{OP}$ is 0.555 and the $\mathrm{R}$ square for $\mathrm{KM}$ plus $\mathrm{OC}$ and is 0.433 . The difference is 0.122 that mean the organization culture is impeding the organization performance.

\section{Table 2: Organization Culture Descriptive Statistic}

\begin{tabular}{lllll}
\hline & $\mathrm{R}$ & $\mathrm{R}$ Square & $\begin{array}{l}\text { Adjusted R } \\
\text { Sqaure }\end{array}$ & Sig \\
\hline Model & $.658^{* *}$ & .433 & .432 & .000
\end{tabular}

Predictors: (constant), OCAVR

Dependent variable: KMPAVR

From the Table 3, the correlation between the Independent variables (KM and OC) combined and OP, it can be stated that according to the score of Pearson analysis $(0.691)$ there is a strong positive relationship between the independent variables and organizational performance.

Table 3: Organizational Performance (OP) Descriptive Statistics

\begin{tabular}{llll} 
& IV,OCAvrg & OPAvrg \\
\hline & Pearson Correlation & 1 & $.691^{* *}$ \\
& Sig. (2-tailed) & & .000
\end{tabular}


${ }^{*}$. Correlation is significant at the 0.01 level (2-tailed).

b. Listwise $\mathrm{N}=587$

\section{Discussion and Emphasis on the Effect of Organizational Culture on Knowledge Management and Managerial Performance}

The relationship between knowledge management and managerial performance aligns with the notion that organizations rely on their information systems to create sustainable references for procedure and processes, values, and the exchange of knowledge. Organizational cultures come in as the anchoring environment for both managerial performance and knowledge management that can be used to influence certain outcomes. Knowledge management systems can be anchored upon cultural inclinations such as transformational leadership where regardless of organizational differences a defines pattern of informational engagement is applicable. Use of labor power in a certain way portrays the dynamics of using a particular leadership style and set of values which reflects on performance outcomes (Jahmani, Fadiya, Abubakar, \& Elrehail, 2018). The possibilities are pushed when leaders are able to tap into information systems that works for them in task execution that define knowledge management. Some organizational attitudes and behavior have a better anchoring in defining knowledge management parameters such as knowledge sharing, creation of databases, research and development, and creation of reliable internal procedures and processes. Once a value systems or organizational culture is identified, managerial performance and knowledge become intertwined progressing on the same level in establishing performance efficiencies. However, organizations need to contend with the unpredictability of business environments that sway value systems out of their vision scope. An understanding of this perspective provides the basis for deliberate engagement towards performance counselling where knowledge management meets managerial performance. For instance, the need to adapt to a business environment may force organizations to adopt transformational leadership as its core corporate culture. The outcome of this aligns with better positioning in knowledge sharing as a vital component in knowledge management and better influence on subordinates through positive reinforcement. Knowledge management emerges as a marker for organizational responsiveness to create sustainable performance criteria while organizational culture provides the functional environment.

Organizational effectiveness is a component of managerial performance that relies on various organizational resources. Knowledge management is one of the resources fundamental to organizational effectiveness where managers can tap into to create models that align with a stipulated vision. Models used in achieving organizational effectiveness apply information gained from individuals and organizational learning that allows for appropriate systems procedures and processes (Singh, 2017). Use of the system resource model reveals the need for proper use of valued resources and appreciation of their scarcity to ensure effective uptake. Other areas considered a part of managerial performance include the planning ability, development of subordinates, flexibility, conflict management, and problem solving. These aspects of managerial performance are linked to the organizational culture in the sense that certain attitudes and behavior need to be in place to push their application. Knowledge management contributes to this in form of information development and documenting through internal procedures and processes, internal patents, meetings, R\&D activities, and brainstorming sessions. Furthermore, managerial performance relies on a shorter response time which can be attained by having an improved knowledge management system and strategy. The level of effectiveness in decision-making defines an organization's corporate culture which in turn spurs managerial performance highlighted in the level of coordination involving subordinates in their respective roles. Managers cannot achieve organizational effectiveness without using knowledge management systems where every organization goes into to understand its customers, employees, and its industry among other stakeholders. Once an organization streamlines its managerial strategies and knowledge management systems based on 